\title{
Author Spotlight: Lorenzo Serafini
}

\section{Lorenzo Serafini $^{1}$}

Published online: 17 April 2020

(c) Springer Science+Business Media, LLC, part of Springer Nature 2020

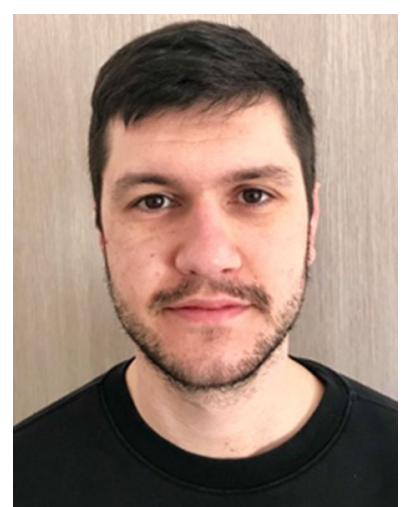

Lorenzo Serafini is currently a 6th-year student at the University of Bologna Medical School, scheduled to graduate in June 2020. He also has worked abroad, spending a month as a surgical intern at the University Medical Center of Groningen in the Netherlands, Department of Hepatopancreatobiliary Surgery. His main interest is the study of rare tumors of the abdomen in the field of General Surgery, an area that he intends to incorporate into his profession.

Publisher's Note Springer Nature remains neutral with regard to jurisdictional claims in published maps and institutional affiliations.

Lorenzo Serafini

lorenzo.serafini264@gmail.com

1 University of Bologna, Bologna, Italy 